\title{
Junctures in Etulo Verb Serialization
}

\author{
Adaobi Ngozi Okoye \\ Department of Linguistics, Nnamdi Azikiwe University, Awka, Nigeria
}

\begin{abstract}
Verb serialization involves the use of two or more verbs in the expression of series of related events. This feature has been established for West African languages and also for Etulo, an Idomoid language of the Benue Congo language family. This present study examines verb serialization in Etulo in order to ascertain the juncture types that can be confirmed for the language. The study adopts the Role and Reference Grammar theoretical approach in the analysis of the data. Data for the study were elicited from Etulo native speakers resident in Adi, Buruku Local Government Area of Benue State, Nigeria. Based on the analysis of the collected data, the study confirms both nuclear and core junctures for Etulo language. Furthermore, these junctures are distinguished on the basis of argument realization and sharing in the language.
\end{abstract}

Index Terms — serial verb construction, juncture, argument, role and reference grammar, Etulo

\section{INTRODUCTION}

The phenomenon of serial verb constructions is common to most West African languages. According to Aikhenvald (2006) serial verb constructions describe what is conceptualized as a single event. Dixon (2006) agrees with Aikhenvald's view and further adds that the multiple verbs in a Serial Verb Construction, conceived of as describing a single action can sometimes, but not always, be analysed into sub events that relate to one verb. In a serial verb construction, two or more verbs are put together. These verbs form a complex predicate which expresses series of related events. Based on a general characterization, serial verbs share arguments, lack connectives and in addition share grammatical categories among other cross-linguistic characterizations proposed for serial verb constructions.

Earlier study in Serial Verb Construction in Etulo (Ezenwafor 2019) discusses Serial Verb Construction hereafter SVC based on the typological criteria proposed in Aikhenvald (2006). Based on the criteria, Ezenwafor (2019) observes that Etulo SVC perform both semantic and grammatical functions. The study further establishes types of SVC to include symmetric versus asymmetric, contiguous versus non-contiguous and optional versus obligatory types. In addition, Ezenwafor (2019) asserts that the range of meaning expressed by Etulo SVCs include but not limited to benefactive, instrumental, accompaniment, completive etc. The author with regard to the characterization of SVCs submits such features as mono clausality, argument sharing, argument and switch function among other typological features. Ezenwafor (2019) essentially classifies SVCs in Etulo based on some features attested for SVCs cross linguistically and further distinguishes Etulo SVCs from a similar multi verb construction referred to as consecutive construction. The present study however departs from Ezenwafor (2019) as it examines Etulo SVCs adopting the Role and Reference Grammar framework espoused in Van Valin \& Lapolla 1997; Van Valin 2005). Specifically, the paper studies the logical structure of Etulo SVCs in addition to accounting for the types of junctures attested in Etulo SVCs. Based on the layered structure postulated in RRG framework, a distinction is made between nuclear and core serialization in the classification of SVCs. In the present study, the terms serialization and serial verb constructions (SVCs) are used interchangeably.

The rest of the paper is organized as follow: Section 2 reviews related literature while Section 3 discusses the theoretical framework adopted in the study. Section 4 discusses the juncture types attested in Etulo SVC. Section 5 forms the conclusion of the study. The next section goes into the review of some works on SVC.

\section{STUDIES ON SVC}

SVC comprises sequences of verbs which are not connected by conjunction markers and form a single clause. Some common features have been assumed in the characterization of SVC based on cross linguistic investigations, (Baker 1989, Collins 1997, Aikhenvald 2006, Dixon 2011). These features include lack of conjunctions, sharing of arguments, sharing operators such as tense, aspect, mood, intonation, juxtaposition of two or more verbs and denoting of single event

Baker (1989) opines that SVCs are constructions in which a sequence of verbs appear in a single clause. The author further observes that the verbs in a series have a single subject and share logical objects. Foley and Olson (1985) in Caesar (2016) view SVCs as constructions in which verbs sharing a common subject and object are merely juxtaposed without any intervening conjunction. Collins (1997) also agrees with these authors on argument sharing among verbs in a series. These agreements notwithstanding, concerns have been raised and proposal made with regard to the issue of SVCs expressing a single event. For instance, Schultze-Berndt (2000) has observed the difficulty associated with the application of this feature to cross-linguistic data. On the other hand, Bohnemeyer, Enfield, Essegbey, IbarretxeAntuñano, Kita, Lüpke and Ameka (2007) propose the Macro-Event property which requires a shared reference among 
sub-event within a macro-event. The macro event property also entails that categories such as tense and temporal adverbials should have one value in a serial verb construction. This proposal too also has cross-linguistic variations.

Emenanjo (2015) asserts that from existing literature, SVCs have the following features: verb or verb phrases are in a row or series, the first verb bears all the inflectional markers for tense, aspect and negation and all verbs share the same subject, the verbs in a series lack overt connectors among other features.

Chang (2007) adopting the Role and Reference Grammar framework examines resultative and serial verb constructions in Mandarin within the Role and Reference Grammar framework in order to account for how NP arguments are linked to syntax in the two different constructions. The study which is concerned with the argument realization patterns in Mandarin SVCs adopts two diagnostics to distinguish the resultative construction from SVCs in Mandarin. The study argues that participants roles which the arguments play in the logical structure determine their linking to syntax .Chang 2007 concludes that in Mandarin SVCs, the first Actor is linked to the Privileged Syntactic Argument position, the undergoer1 is linked to the position immediately following the first verb, while the undergoer2 is linked to the position immediately following the second verb. The second Actor is further linked to the position immediately following the first verb.

Within the framework of the RRG, Fan (2016) accounts for SVCs in Mandarin Chinese and Jinjiang Southern Min. The author develops some diagnostics and applies them to the data drawn from Mandarin Chinese and Jinjiang Southern Min .The established diagnostics to distinguish sub-types of SVCs are inter-clausal and intra-clausal. The inter-clausal diagnostics include independent negation, passivisation of the object of V2, independent modification by temporal adverbial, independent marking of viewpoint aspect, independent modification by manner adverbial, prosodic structure and the coordinate structure constraint while the intra- clausal diagnostic involve passivization of the first object, co-ordination within the SVC, insertion of intervening material and obligatory topicalization of the undergoer argument. Based on the inter-clausal diagnostics, Fan 2016 draws the line between SVCs and bi-clausal structures while based on the intra-clausal diagnostics, the difference between nuclear and core types of serialization in Mandarin Chinese and Jinjiang Southern Min are established.

In another separate study, Tao (2009) provides an analysis of SVC in Mandarin Chinese focusing on the internal structures of the clause with the view to examine the syntax-semantic interface of the complex sentence. The study employs the theoretical proposal of clause linkage developed in Role and Reference Grammar. The author proposes three general types of serial verb constructions in Chinese and observes that the choice of operators at each juncture is determined by the verb semantics. The study adds that lexicalization and grammaticalization of the verb is a common feature shared at various degrees by the three Chinese serial verb construction types.

Conor (2013) examines SVC in Pitjantjatjara and Yankuntjatjara, two dialects of Western Australia. The study examines multi verb sentences in order to ascertain the juncture level and nexus types as well as show the scope of operators. The author observes that in Pitjantjatjara and Yankuntjatjara, clauses can be joined by munu or ka to show same or different subjects respectively and to reflect switch reference. The author exemplifies thus

1a.Wati-ngku papa pu-ngu munu mira-ngu

Man-ERG dog-ABS hit-PAST and cried out-PAST

the man hit the dog and he cried out

b. Wati-ngku papa pu-ngu ka mira-ngu

Man-ERG dog-ABS hit-PAST and cried out-PAST

The man hit the dog and it cried out

Conor (2013:51)

In the examples culled from Conor (2013:51), the conjunction munu in 1a suggests the subject is the same entity that cried out while $\mathrm{ka}$ in $1 \mathrm{~b}$ implies that the subject is different from the entity that cried out.

A further observation by Conor (2013) shows that multi verb sentences display switch reference in dependent verb forms. In addition, the author avers that both dialects use serialized verbs to indicate series of action or a compound verb. With regard to the nexus juncture relation, Conor observes that both dialects manifest tight and loose serialization. Whereas the latter form of serialization has verbs that may have their own arguments and modifiers, the former serialization share arguments and modifiers. Conor 2013 illustrates with the examples following
2a.Paluru nyiinyii ya-nkula $\mathrm{V}$
3SG NOM zebra:finch-ABS go-SERIAL get-PAST

She went and got zebra finch (droppings)

do'(3SG, [go-get'(3SG)]

$\begin{array}{llc}\text { b.Paluru } & \text { ya - nkula, nyiinyii } & \text { ura- nu } \\ & \mathrm{V} & \mathrm{V}\end{array}$

3SG NOM go-SERIAL zebra:finch-ABS get-PAST

Having gone, she got zeb ra finch

do' (3SG,[go'(3SG)]\& do' (3SG,[get'3SG, zebra finch)]

The logical structure of $2 \mathrm{a}$ shows that the arguments are shared thus it is tight while that of $2 \mathrm{~b}$ reveals that the verbs are split by an intervening argument hence it is loose. 
Caesar (2016) examines the syntactic and semantic properties of SVC as well as the functional types of Serial Verb Construction in Dangme. The study carried out within the Role and Reference Grammar Theoretical Approach avers that Dangme Serial Verb Constructions are characterized by such properties as the subject being expressed once on V1, verbs not linked overtly by co-ordination or subordination and the verbs expressing a complex event which occur simultaneously at the same location. Having examined some works relevant to the present study, the next section shall explicate the approach adopted in the study.

\section{THEORETICAL BACKGROUND}

The Role and Reference Grammar framework hereafter RRG is adopted in the description of Etulo SVCs. RRG is a theoretical approach first proposed by Foley and Van Valin (1984). The theory was developed in Van Valin (1993a) and further developed in Van Valin \& La Polla (1997) and Van Valin (2005). Within the RRG theoretical framework, the structure of the clause is captured in a model referred to as the Layered Structure of the Clause (henceforth LSC). The LSC primarily constitutes the nucleus, the core and the periphery. The nucleus contains the predicate (usually a verb), the core contains the nucleus and the arguments of the predicate while the periphery is made up of the non-arguments of the predicate (peripheral adjuncts and modifiers of the clause). As opined by Van Valin, the three components of the LSC constitute the essential building blocks of complex sentences in human language. RRG captures the construction of complex sentences in what is termed junctures. Junctures concerns the nature of units being linked. Consequently complex sentences could involve combining nuclei with nuclei, core with core or clauses with clauses. Nexus relations involve the syntactic relations between units in a complex construction. As a result, there are three levels of junctures and three possible nexus relations among the units in the junctures.

In a nuclear juncture, two or more nuclei combine to form a single complex nucleus with a single set of core argument. Core juncture involves two nuclei, each having its own set of core arguments resulting in two separate cores. In a non-subordinate core, the linked units share one core hence there is an overlap while in a subordinate core juncture, the linked units function as a core argument of the matrix verb. Clausal junctures involve sentences comprising several clauses.

Having explained the aspects of the theoretical framework adopted in the study, we shall demonstrate the structure of the clause in Etulo before going into the discussion of SVCs

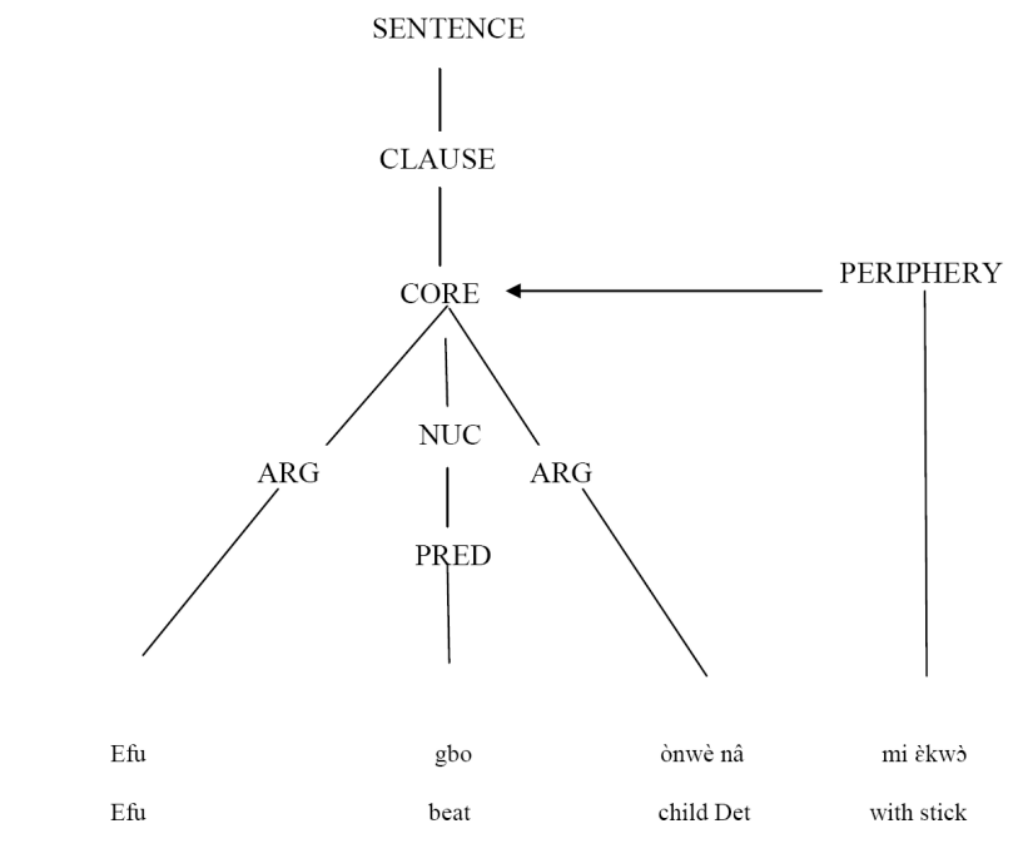

Efu beat the child with a stick

Figure 1 Formal representation of the LSC in Etulo

The Etulo sentence represented graphically in figure 1 shows the core and the periphery of the clause in Etulo. The core is the unit containing the nucleus $g b o$ 'beat' and the arguments in the semantic representation of the predicate Efu and Ònwè nâ 'the child'. The periphery contains the prepositional phrase mi غ̀kwj̀ 'with a stick' which is not an argument of the predicate but an element of the clause that is left outside the core. Van Valin and La Polla assert that this distinction into the core and the periphery is a universal aspect of the LSC.

It should be noted that the basic word order in Etulo is SVO. (Okoye 2019) Besides, since establishing the clause structure entails identifying grammatical functions, we provide example below which shows the transitive clause in Etulo. 


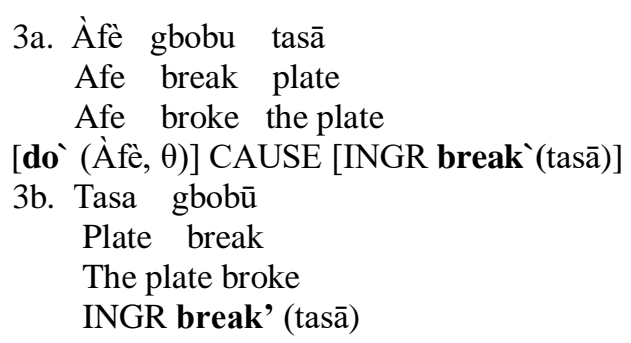

Example shows $3 a$ transitive clause in Etulo and its logical structure while example $3 b$ shows an intransitive clause in Etulo. The logical structure reveals the two arguments of the verb. In 3a Afe is the Actor, a willful agent who instigates an action while tasa 'plate' is the patient, an entity which undergoes a change of state and condition described by the verb gbobu 'break'. The patient is subsumed under the undergoer macro-role in RRG. This means that the core arguments function as subject and object regardless of their semantic roles. In 3b, the logical structure shows the verb's single argument which is the undergoer. Notice that the only argument of the intransitive verb is realized as the subject, its semantic role notwithstanding.

The semantic interpretation of an argument in RRG is a function of the logical structure in which it is found. The semantic relation between a predicate and its arguments is referred to as thematic relations. Semantic relations do not apply independently rather they are grouped into five namely: Experiencer, Agent, Theme, Patient and Recipient.

The terms (macrorole) proposed in RRG to be used for the two arguments of a transitive verb are 'Actor' and 'Undergoer'.Van Valin (2005) posits that the term " macrorole" is used because it subsumes a number of thematic relations. The author asserts that actor is a generalization across agent, experiencer, instrument etc while undergoer subsumes patient, theme and recipient. The two semantic macro-roles namely actor and undergoer, are equivalent to the primary arguments of a transitive predication that are referred to as subject and object within earlier frameworks. Van Valin asserts that the choice of a macrorole is determined by the semantic structure of the verb and that the decisive feature is the presence of an activity predicate in the logical structure thus intransitive verbs such as run and die will be assigned different macroroles because of their logical structure. The logical structure of a verb aids in predicting the number of arguments, which the verb can take.

Operators in RRG refer to such grammatical categories like aspect, tense, negation and illocutionary force. These operators modify specific layers of the clause. They represent grammatical categories, which are different from predicates and argument (Van Valin and Polla1997:40). Taking aspect for instance, we observe that aspect is a nuclear operator as shown in example 4 below

$$
\text { 4.Áni lè gye ungwogyē }
$$

ISG PROG eat food to eat

I am eating

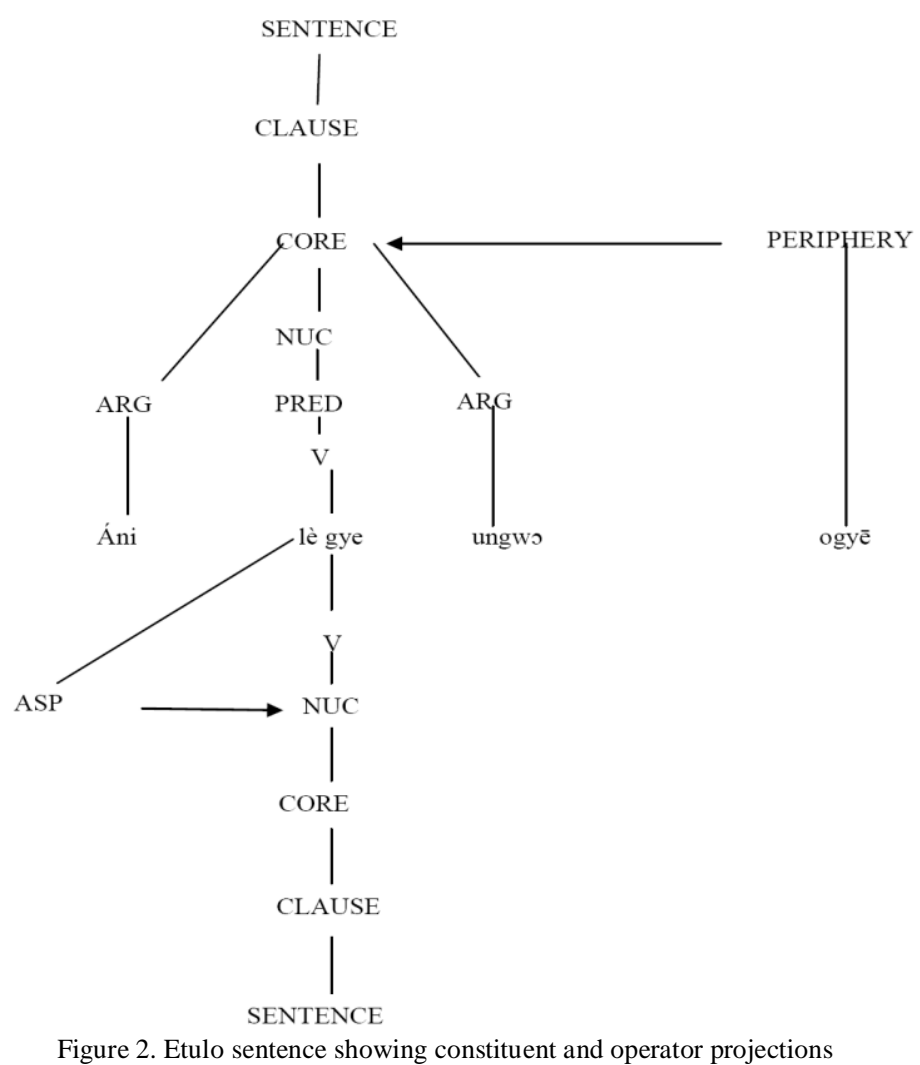


The diagram in figure 2 has two projections. The top part is the constituent projection while the bottom part is the operator projection. The two projections are joined through the nucleus, which is the central element in the clause. The arrow indicates the scope of the operator. The diagram reveals that aspect is a nuclear operator in Etulo

We now turn to junctures in Etulo SVCs in section 4

\section{JUNCTURES IN ETULO SVC}

A canonical SVC within the theoretical proposal of RRG is a construction with series of verbs co-depending on each other. SVCs are constructions containing more than one verb with no intervening conjunction. Some expressions instantiating SVC in Etulo are shown in 5a-g. The verbs in series within the sentential constructs are rendered in italics

5a.Efu tse j̀nyà kàkà òzû

Efu run race enter house

Efu ran into the house

[two nuclei, tse j̀nyà \& kàkà, in a single core]

b. ìkutsê na mùnù kakà ìshe

stone DET roll enter hole

The stone rolled into the hole

[two nuclei, mùnù \& kakà in a single core]

c. Efu wawā fa òyombo èkyò

Efu swim cross across river

Efu swam across the river

[two nuclei wawā \& fa in a single core]

d. Ènwè ònjá gbe ònòdzì tsô òtsètsê

Children woman park picture show teacher

The girls showed pictures to the teacher

[two nuclei gbe \& tsô in two separate cores]

e. $\mathrm{O}$ kà kye ùdzà mgban nu mā

3SG FUT take money his own give 3PL

He will give them his own money

[two nuclei ùdzà \& $n u$ in two separate cores]

f. Efu kyē Afe gya

Efu take Afe sell

Efu betrayed Afe

[two nuclei kye \& gya in two separate cores]

g. Efu kyé ùdzà désó nū óníkyōǹ

Efu take money send give grandmother $3 \mathrm{SG}$

Efu sent money to his grandmother

[three nuclei kyé , désó \& $n \bar{u}$ in two distinct cores]

The Etulo expressions in examples 5a-g comprise more than one verb. The verbs in series occur without any conjunction. Examples 5a-c, have multiple verbs that are next to each other. The verbs share the same subject and object. In addition, the verbs indicate motion. Examples 5d-g, show verbs which are separated by their object $\mathrm{Np}$, hence they share the same subject but not the same object. In all instances, the shared subject precedes the first verb.

Within the RRG theoretical framework, the examples in 5a-g are analyzed as junctures that is, based on the connection between the units. Examples 5a-c are instances of nuclear junctures because they represent cases of a single core containing multiple nuclei. In example 5d, ònòdzì 'picture' is the object of the second verb show.

Examples d-f are clauses made up of multiple cores. Van Valin and La polla (1997:445) note that it is impossible for two nuclei to be adjacent in a core juncture. The Etulo sentence in $5 \mathrm{~g}$ comprises both core and nuclear junctures. The constituent projections for example $5 \mathrm{a}$ is shown in figure 3 below 


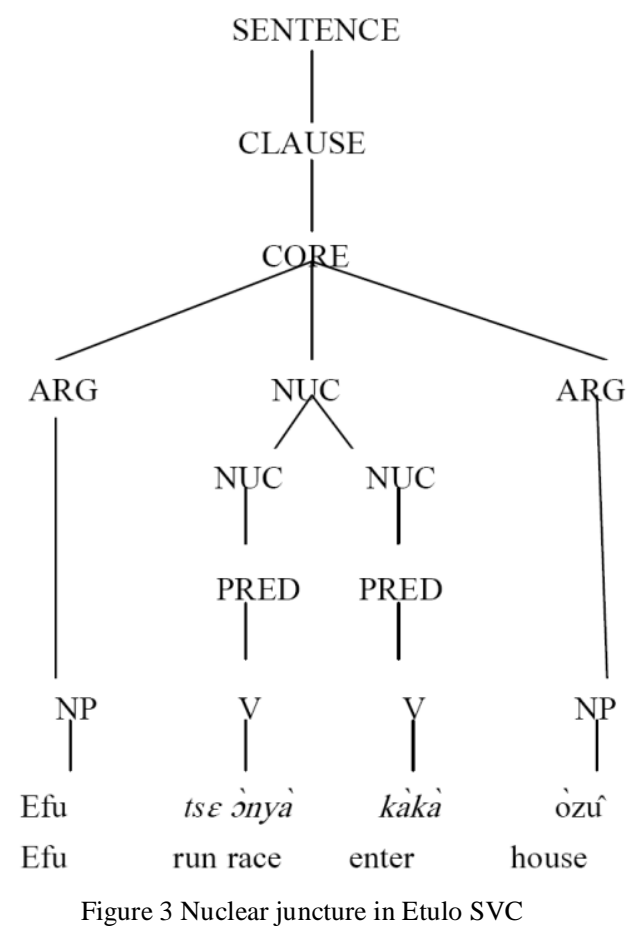

From the diagram in figure 2, one observes that the nuclei take up a single set of argument in the core. Thus, the constituent structure shows that both arguments (Efu and òzû) are shared. This is further elucidated by the logical structure of example 3 a repeated here as example $6 \mathrm{a}$

6a. Efu tse j̀nyà kàkà òzû

Efu run race enter house

Efu ran into the house

do' (Efu, [ ts $\boldsymbol{\varepsilon}$ ’̀nyà kàkà run'(Efu, òzû )] ) \& BECOME be-at' (òzû, Efu)

From the logical structure in 6a, the arguments of the verbs are made explicit. Efu is assigned the actor while ozu is the goal and translates to Undergoer within the RRG framework. Notice also that the verbs share both subject and object arguments.

The constituent projection in figure 3 is different from the constituent projections for examples $5 \mathrm{~d}$ and $\mathrm{g}$ illustrated in figures 4 and 5 below

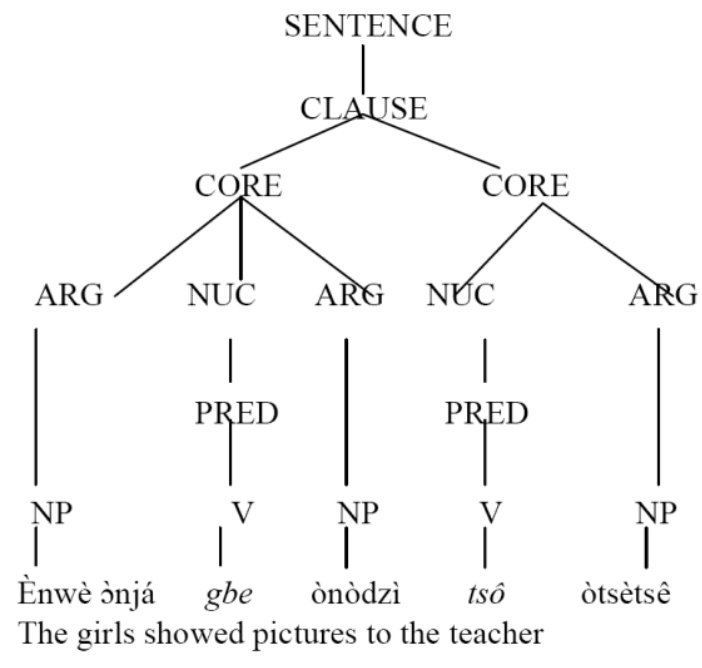

Figure 4 Core junctures in Etulo 


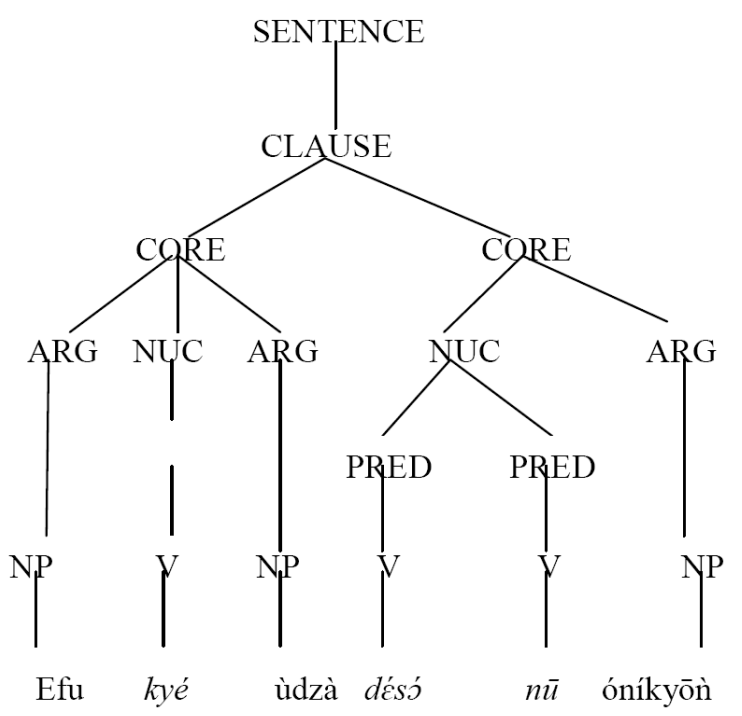

Efu sent money to his grandmother

Figure 5 Core coordination in Etulo revealing coordinate nexus

The Etulo examples represented graphically in figures 4 and 5 contain two distinct cores and instantiate three place predicates where the leftmost arguments (Ènwèònjá 'girls' and Efu) are assigned actors, ònòdzì 'picture' and ùdzà 'money' are undergoers while òtsètsê 'teacher' and óníkyō 'grandmother' are the non-macro role core arguments.

Figure 4 instantiates core juncture in Etulo while figure 5 shows core coordination in Etulo.

In a nuclear juncture in Etulo, the verbs share arguments hence functioning as a single predicate. However, within a core juncture, the verbs may have independent arguments but must share one core argument usually the subject argument.

\section{CONCLUSION}

This study has accounted for Etulo serial verbs following the RRG framework. The study based on the available data shows that Etulo SVCs attest both the nuclear and core junctures. Nuclear junctures represent cases of a single core containing multiple nuclei while core juncture involves two nuclei with their own set of core arguments resulting in two separate cores as shown in figures 4 and 5.

In terms of argument realization, the second verb in the Etulo serial verb construction examined does not realize its syntactic subject argument independently. The SVC with nuclear juncture possesses a single set of syntactic arguments. The sole argument of the second verb in Etulo core juncture is realized as the object of the second verb. This contrast what obtains in an intransitive clause where the single argument corresponds to the subject as earlier shown in example 3b. The SVC revealing core junctures have the same subject as the nuclear juncture.

The study has also shown co-ordinate nexus in Etulo core junctures. Though it has been pointed out by Van Valin that all junctures and nexus relations are not to be found in a particular language, the study calls for further research with regard to complex sentences in Etulo as it may perhaps help to establish more junctures and nexus relations for the language.

\section{REFERENCES}

[1] Aikhenvald, A. Y. (2006). Serial verb constructions; A typological perspective. In Serial Verb Constructions: A Crosslinguistic Typology. Alexandra, Y. A. and R. M. W. Dixon (Eds.). Oxford University Press; 1-68.

[2] Baker, M. (1989). Object sharing and projection in serial verb constructions. Linguistic Inquiry 20: 513-553.

[3] Bohnemeyer, J., N. J. Enfield, J. Essegbey, I. Ibarretxe-Antuñano, S. Kita, F. Lüpke and F. K. Ameka. (2007). "Principles of event segmentation in language: The case of motion events." Language 83(3): 495-532.

[4] Bril, I. (2007). Nexus and Juncture Types of Complex Predicates in Oceanic languages: Functions and Semantics. Language and linguistics (Academia Sinica), vol.8 (n1), pp.267-310. ffhalshs00281187.

[5] Caesar, R. (2016). Serial verb constructions in Dangme. Journal of literature, languages and linguistics. 20: 32-43

[6] Conor, P. (2013). "Serial Verb Constructions in Pitjantjatjara and Yankunytjatjara,. ITB journal vol 141 article 3.

[7] Chang, J. (2007). Linking Semantics and Syntax in Mandarin Serial Verbs: A Role and Reference Grammar Account. Language and Linguistics 8.1:235-266

[8] Dixon, R. (2006). Serial verb constructions: Conspectus and coda. In serial verb constructions: A cross-linguistic typology. Alexandra, Y. A. and R. M. W. Dixon (Eds.). Oxford University Press 338-350.

[9] Dixon, R. M. W. (2011). "Serial Verb Constructions in Dyirbal." Anthropological Linguistics 53(3): 185-214.

[10] Durie, M. (1997). Grammatical structures in verb serialisation. Complex Predicates. A. Alsina, J. Bresnan and P. Sells. Standard: Center for Study of Language and Information. 289-354. 
[11] Emenanjo, E. (2005). Igbo verbs transitivity or complementation. In Ozo-mekuri, N. (Ed).Trends in languages and linguistics in Nigeria. A festschrift for P.A. Nwachukwu. Port Harcourt: Grand orbit and Emhai Press.479-497.

[12] Ezenwafor, C.I. (2019). Serial Verb Construction in Etulo. Theory and Practice in Language Studies, Vol. 9, No. 9, pp. 12211230

[13] Fan, Y. (2016). Serial Verb Construction in Mandarin Chinese and Jinjiang Southern Min. PhD Dissertation. University of Manchester

[14] Okoye, A.N (2019) Etulo Verb Structure. International Journal of Language and Linguistics. Vo 16(4)123-130

[15] Schultze-Berndt, E. (2000). Simple and complex verbs in Jaminjung. A study of event categorization in an Australian language. Ph.D., University of Nijmegen

[16] Tao, L. (2009). Serial Verb Construction in Mandarin Chinese: The interface of syntax and semantics Proceedings of the 21st North American Conference on Chinese Linguistics (NACCL-21). Volume 2. Edited by Yun Xiao. Smithfield, Rhode Island: Bryant University. Pages 209-228.

[17] Van Valin R. and Lapolla, R. (1997). Syntax, Structure, Meaning and Function. Cambridge: Cambridge University Press.

[18] Van Valin, R. (2005). Exploring the Syntax-Semantics Interface. Cambridge: Cambridge University Press.

Adaobi Ngozi Okoye is a lecturer at the Department of Linguistics, Nnamdi Azikiwe University, Awka, Nigeria. 